\section{The Knights' Move}

IT is not often that distinguished scientists march out from the confines of their own speciallisms to do battle in strange territory, but in lectures published this month, both Sir Solly Zuckerman and Sir Peter Medawar have had remarks to make about the philosophy of science. Both of them seem to be fighting under very similar colours. The position the two knights are defending is that of scientific truth, whose subtle nature is in danger of being bruised, it is implied, by foes not always distinguishable from sociologists and structural anthropologists. Sir Solly and Sir Peter are also calling on the philosophers who form the territory's home guard to admit a greater role for imagination in the process of scientific discovery.

The methodology of the natural sciences has for the most part been worked out by professional philosophers rather than scientists as such, and the philosophers have tended to dwell, both by interest and the tools of their trade, on only one half of the process of discovery, the procedure whereby a hypothesis is ratified and its cognitive status established. With some exceptions they have ignored, or not fully treated, the process whereby the hypothesis is first reached; logic, they say, is our business, serendipity, visitations of the muse and the other imaginative leaps that lead the scientist to his cry of heureka, lie in the province of psychologists. The result of this quite proper demarcation is that the framework built by the philosophers seems incomplete to professional scientists; it appears to cast them as logical automata who need no spark of imagination to ignite their mental processes.

This is why Sir Solly Zuckerman, in his Astor lecture "Attitudes to Enquiry and Understanding", derides as "total nonsense" the popular misconception that the scientific process is always an orderly one and that "scientists, as it were, constitute a dispassionate body of men and women who, through training and experience, are all but interchangeable". Sir Peter Medawar makes much the same point in his Romanes lecture "Science and Literature" (Encounter, January 1969); referring presumably to the philosophers or their popular interpreters he says "this official view - of the complete accountability of science to reason-is no longer believed in by most people who have thought deeply about the nature of the scientific process".

Sir Solly and Sir Peter are unanimous that the faculties of criticism and imagination are the pieces that are missing from this picture. "The scientific process", Sir Solly says, "is necessarily a process of enquiry which combines searching with questioning, and leaps of imaginative understanding with critical disbelief." Sir Peter, who supports his analysis with a disquisition on the nature of poetic truth, declares that "scientific reasoning is at all levels an interaction between two episodes of thought, a dialogue between two voices, the one imaginative and the other critical. ... In this conception of the scientific process, imagination and criticism are integrally combined".

Their defences fortified, the two knights make pre-emptive attacks on those who have won themselves the title of social scientists. There are some who believe that social scientists pay so much envious attention to the methodology worked out by the philosophers for the natural sciences that they contort their work to fit a straitjacket which does not properly suit it. The opposite view is taken by Sir Solly and Sir Peter. A percipient analysis leads Sir Solly to remark, "Objective truth exists in the social sciences, but it is far more difficult to find, and its achievement necessitates a clear appreciation, and an admission of the value judgments of the researcher. Concealing them, in the pretence of objectivity, leads only to confusion and delusion-and to writings which mislead because of their presumed objectivity".

Sir Peter believes that there is "evidence of the beginnings of a whispering campaign against the virtues of clarity", a style of thought or writing that "has had a deplorable influence on the quality of modern thought in philosophy and in the behavioural and 'human' sciences". A principal target of his remarks is those systems of thought whose only claim to scientific status is that their axioms are consistent among themselves but not necessarily with truth. Such systems, Sir Peter believes, include Freudian theory and the structural anthropology of M. Claude Lèvi-Strauss.

In one sense, at least, the demands that Sir Solly and Sir Peter are making on the philosophers of science seem a trifle greedy. Having pegged out the boundaries of the citadel where scientific truth resides, they want the back entrance to be fortified more strongly against the social scientists, yet at the same time they desire the lush pastures of imagination to be enclosed within the castle's walls. Philosophers will doubtless take serious note of what the two knights have to say, but it is hard to say how far they will agree with their tactics for defending truth. The claim of one branch of enquiry to be "purer" than another is, for philosophers, a somewhat barren issue, except in the special case of reducibility. Sir Peter makes the charge that "what should be the equivalent in science of literary criticism is represented by a great emptiness which is a reproach to all scholars, scientists and humanists alike". But philosophers, at least, are unlikely to be mortified by this reproof. They have said all along that imagination is not their business. 